\title{
Synthesis and characterization of poly(2,5-dimethoxyaniline) and poly(aniline-Co-2,5-dimethoxyaniline): The processable conducting polymers
}

\author{
BIDHAN C ROY, MAYA DUTTA GUPTA, LEENA BHOWMIK and JAYANTA K RAY* \\ Department of Chemistry, Indian Institute of Technology, Kharagpur 721 302, India
}

MS received 1 March 2001

\begin{abstract}
Poly(2,5-dimethoxyaniline) (PDMOA) and its copolymers with aniline (PADMOA), which exhibit remarkably improved solubility in common organic solvents, were obtained by chemical polymerization, and characterized by a host of physical techniques. The lowering of the quinoid absorption in the IR spectra and the upshifting of the $\mathrm{N}_{1 \mathrm{~s}}$ envelope in the XPS spectra indicate residual doping in the XPS polymers and thermal characteristic of the polymers provide evidence for hydrogen bonding, which appear to enhance the thermal stability of the homopolymer. These polymers are highly planar and conjugated, with well-developed polaronic features, shown by the XRD, ESR and UV-spectral data. The conductivity, however, is not high and apparently may be due to localization of polaronic charges at the hydrogen-bonding sites and the increased proportion of the insulating methoxy component in the polymer matrix.
\end{abstract}

Keywords. Poly(2,5-dimethoxyaniline); poly(aniline-Co-2,5-dimethoxyaniline); conducting polymer.

\section{Introduction}

Conducting polymer with polyaromatic back bone including polypyrrole, polythiophene, polyaniline etc has received a great deal of attention in the last two decades. Polyaniline has attracted attention because of its electronic, electrochemical and optical properties and environmental and thermal stability (Stotheim 1987; Macdiarmid et al 1989; Genies et al 1990; Olinga et al 2000; Ruckenstein and Yin 2000). Polyaniline, however, is severely limited in view of its insolubility in common organic solvents making its characterization rather intricate. Recently, synthesis of some substituted polyanilines which are soluble in organic solvents as well as in water beside being thermally and environmentally stable have been achieved (Watanabe et al 1987; Aurian-Blajeni et al 1988; Somasiri and MacDiarmid 1988). In order to obtain materials with superior electrical and optical properties we have selected dimethoxy aniline derivative in this investigation, which is polymerized to get more regular and processable conducting polymer. In this paper, we report here the chemical synthesis and characterization of homopolymer of 2,5-dimethoxy aniline and its copolymer with aniline (PADMOA) (figure 1). A better rationalization of structure, property correlation should be possible in case of dimethoxy substituted polyaniline systems where steric, electronic and other effects generated by

\footnotetext{
*Author for correspondence
}

substituents are expected to enhance their potentiality as novel materials (Wei and Hsuch 1989; Chan et al 1992, 1993, 1995; Leclerc et al 1993; Ray et al 1995, 1999).

\section{Experimental}

Aniline was doubly distilled and 2,5-dimethoxy aniline was sublimed at reduced pressure prior to polymerization and commercial ammonium persulfate was used without purification. Polyaniline (PAN) and poly(2,5-dimethoxyaniline) (PDMOA) were synthesized by chemical oxidation of their respective monomer using $\left(\mathrm{NH}_{4}\right)_{2} \mathrm{~S}_{2} \mathrm{O}_{8}$ as initiator (Focke et al 1987; Cromack et al 1991).

In a $100 \mathrm{ml}$-conical flask required amount of 2,5dimethoxyaniline was dissolved in $1 \mathrm{M} \mathrm{HCl}$ and the solution was cooled to $0-5^{\circ} \mathrm{C}$. To this, prechilled solution of ammonium persulfate dissolved in $1 \mathrm{M} \mathrm{HCl}$ was added drop wise over a period of $25 \mathrm{~min}$ under vigorous stirring. During addition of ammonium persulfate solution deep blue colour developed rapidly. The resultant reaction mixture was stirred at that temperature for another $4 \mathrm{~h}$, when a blue precipitate gradually separated which was subsequently collected in a buchner funnel, washed with $1 \mathrm{M} \mathrm{HCl}$ until the filtrate became colourless.

Emeraldine bases were prepared by suspending a part of the virgin polymer in $0 \cdot 1 \mathrm{M} \mathrm{NH}_{4} \mathrm{OH}$ solution. The $\mathrm{HCl}$ doped polymer was prepared by suspending virgin polymer in $1 \mathrm{M} \mathrm{HCl}$ solution. The elemental analysis of the $\mathrm{HCl}$ doped emeraldine gave $\mathrm{C}=55.46 \%, \mathrm{H}=5 \cdot 12 \%$, $\mathrm{N}=7 \cdot 82 \%, \mathrm{Cl}=9 \cdot 21 \%$. 
Table 1. Experimental details for the polymerization of 2,5-dimethoxyaniline.

\begin{tabular}{lcccc}
\hline Sample (abbr.) & $f_{1}$ & $\begin{array}{c}\text { Time } \\
(\mathrm{h})\end{array}$ & $\begin{array}{c}\text { Yield } \\
(\%)\end{array}$ & $\begin{array}{c}\text { Conductivity } \\
(\mathrm{S} / \mathrm{cm})\end{array}$ \\
\hline Poly(aniline-Co-2,5-dimethoxyaniline) (PADMOA-16) & $0 \cdot 16$ & 5 & 85 & $9.7 \times 10^{-3}$ \\
Poly(aniline-Co-2,5-dimethoxyaniline) (PADMOA-23) & $0 \cdot 23$ & 6 & 82 & $6 \cdot 2 \times 10^{-3}$ \\
Poly(aniline-Co-2,5-dimethoxyaniline) (PADMOA-30) & $0 \cdot 30$ & 6 & 80 & $4.7 \times 10^{-3}$ \\
Poly(aniline-Co-2,5-dimethoxyaniline) (PADMOA-37) & $0 \cdot 37$ & 5 & 80 & $3.5 \times 10^{-3}$ \\
Poly(aniline-Co-2,5-dimethoxyaniline) (PADMOA-60) & $0 \cdot 60$ & 5 & 70 & $1.7 \times 10^{-3}$ \\
Poly(2,5-dimethoxyaniline) (PDMOA) & $1 \cdot 00$ & 4 & 75 & $3.6 \times 10^{-4}$ \\
\hline
\end{tabular}

Table 2. Solubility and viscosity of polymers.

\begin{tabular}{|c|c|c|c|c|}
\hline Solvent & PDMOA & $\begin{array}{l}\eta_{\text {int }} \text { at } \\
30^{\circ} \mathrm{C}\end{array}$ & PADMOA-37 & $\begin{array}{l}\eta_{\text {int }} \text { at } \\
30^{\circ} \mathrm{C}\end{array}$ \\
\hline $\mathrm{NH}_{4} \mathrm{OH}$ & SS & & IS & \\
\hline $\mathrm{H}_{2} \mathrm{O}$ & IS & & IS & \\
\hline $\mathrm{C}_{6} \mathrm{H}_{6}$ & SS & & IS & \\
\hline $\mathrm{C}_{2} \mathrm{H}_{5} \mathrm{OH}$ & MS & & IS & \\
\hline $\mathrm{CH}_{3} \mathrm{OH}$ & MS & & IS & \\
\hline $\mathrm{CH}_{2} \mathrm{Cl}_{2}$ & S & & IS & \\
\hline $\mathrm{CH}_{3} \mathrm{COCH}_{3}$ & SS & & IS & \\
\hline $\mathrm{CHCl}_{3}$ & $S$ & & SS & \\
\hline $\mathrm{CH}_{3} \mathrm{CN}$ & MS & & SS & \\
\hline THF & SS & & IS & \\
\hline DMF & MS & & SS & \\
\hline DMSO & MS & & MS & \\
\hline NMP & $\mathrm{S}$ & & MS & \\
\hline $\mathrm{H}_{2} \mathrm{SO}_{4}$ & S & $0 \cdot 12$ & S & $0 \cdot 35$ \\
\hline $\mathrm{HCl}$ & SS & & $\mathrm{S}$ & \\
\hline
\end{tabular}

IS, Insoluble; S, Soluble; MS, medium soluble; SS, slightly soluble.

\subsection{Copolymerization}

Poly(aniline-Co-2,5-dimethoxyaniline) (PADMOA) were synthesized by oxidative coupling of aniline with various molar fractions of 2,5-dimethoxyaniline in the feed using ammonium persulfate as oxidant, in an aqueous acid medium at $0-5^{\circ} \mathrm{C}$. Emeraldine bases and salts were prepared in the same manner (table 1).

\section{Results and discussion}

Poly(2,5-dimethoxyaniline) and its copolymer were obtained as finely powdered material by increasing the mol. fraction of the aniline in the feed.

\subsection{Solubility and viscosity}

The homopolymer base, however, is quite soluble in most organic solvents including $\mathrm{CHCl}_{3}, \mathrm{CH}_{2} \mathrm{Cl}_{2}$ and moderately soluble in EtOH, MeOH, THF DMSO and DMF (table 2).

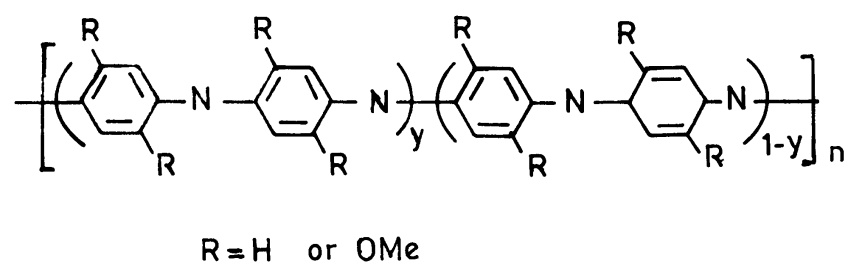

Figure 1. General structure of polymers.

The copolymer (PADMOA) is mainly soluble in NMP and moderately soluble in DMF and DMSO. Both the copolymers are completely soluble in conc. $\mathrm{H}_{2} \mathrm{SO}_{4}(96 \%)$. For improved comparison viscosity measurements were carried out in conc. $\mathrm{H}_{2} \mathrm{SO}_{4}$. The viscosity data qualitatively suggests that the molecular weight of new polymer $\left(\eta_{\text {inst }}=0.12 \mathrm{dl} / \mathrm{g}\right.$ at $30^{\circ} \mathrm{C}$ ) are low as compared to polymer (PAN) $\left(\eta_{\text {inst }}=0.74 \mathrm{dl} / \mathrm{g}\right.$ at $\left.30^{\circ} \mathrm{C}\right)$. The molecular weight of copolymer (PADMOA) $\left(\eta_{\text {inst }}=0.35 \mathrm{dl} / \mathrm{g}\right.$ at $\left.30^{\circ} \mathrm{C}\right)$ is shown to be about three times higher than homopolymer (Zeng et al 1994).

\subsection{IR spectra}

IR spectra of polymer are shown in figure 2 . The benzoid and quinoid stretching appear at $1575-1587 \mathrm{~cm}^{-1}\left(1387 \mathrm{~cm}^{-1}\right.$ in PAN) and $1503-1816 \mathrm{~cm}^{-1}\left(1496 \mathrm{~cm}^{-1}\right)$ (Salaneck et al 1985; Chiang and Macdiarmid 1986; Wang et al 1986; Tang et al 1988; Nguyen and Diaz 1994; Nguyen et al 1994). The lowering of benzoid stretching vibration (7$20 \mathrm{~cm}^{-1}$ ) is due to substituent effect, which increases the level of oxidation especially in homopolymer. The UV-vis absorption spectra (figures 3,4) of the polymers mainly consist of two absorption bands at 286-336 nm and 556$627 \mathrm{~nm}$ attributed to $\pi-\pi^{*}$ transition in the benzoid rings and exciton absorption of the quinoid rings, respectively (Gupta and Umare 1992). The partially soluble HCldoped polymers show $\pi-\pi *$ absorption at $286-336 \mathrm{~nm}$ and exciton transition at $557-597 \mathrm{~nm}$. Concomitant to higher doping level is observed in PADMOA-37 copolymer. The reflectance spectra of the (figure 5) polymer films show large reflection (strong absorption) above $600 \mathrm{~nm}$ taken as evidence of improved conjugation and metallic behaviour (Diaz and KanaZawa 1983). 


\subsection{Thermal analysis data}

Thermal analysis data (figure 6) for PDMOA-HCl and PADMOA-HCL 37 polymers are shown in table 3 . The weight loss of polyaniline and its derivatives is comprised of three major stages (Hagiwara et al 1988; Wei and

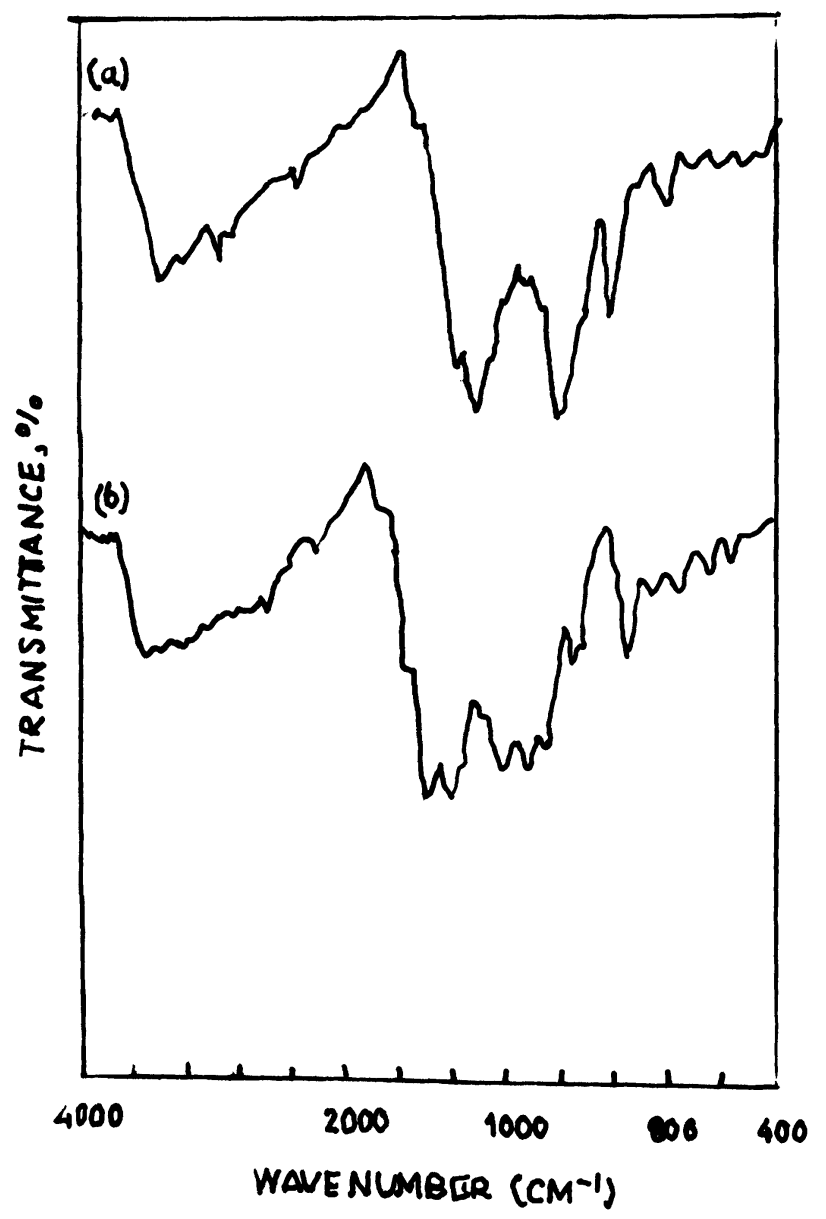

Figure 2. Infrared spectra of (a) PDMOA and (b) PADMOA-37.

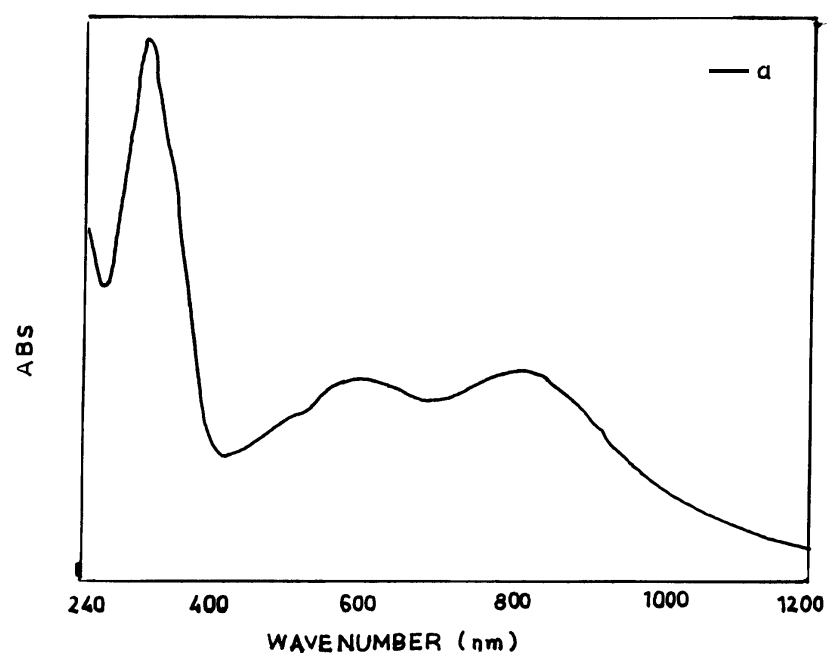

Figure 3. UV-vis spectra of PDMOA base in a. $\mathrm{CHCl}_{3}$.
Hsuch 1989). The minimum weight loss (0-4\%) (except 37 ) in the first stage can be attributed to release of free and bound water dopant which contribute to the endothermic peak in DSC (figure 7). Two endothermic peaks observed in the thermogram of copolymer at $220^{\circ} \mathrm{C}$ and $340^{\circ} \mathrm{C}$ may be assigned to morphological changes (Chan

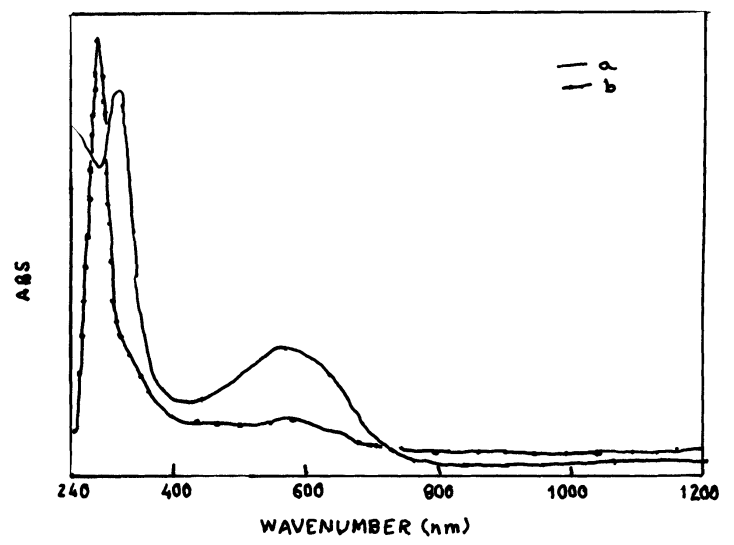

Figure 4. UV-vis spectra of PADMOA-37 in a. THF and b. PADMOA-37 in DMSO.

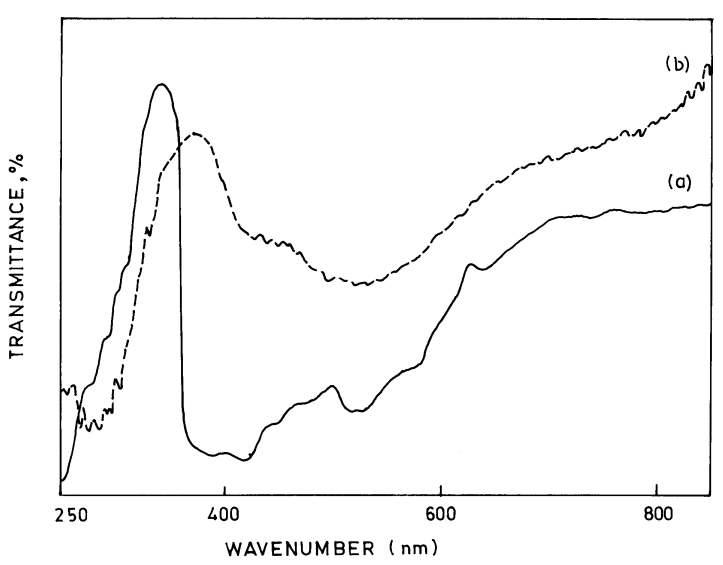

Figure 5. UV-reflectance spectra of (a) PDMOA film and (b) PADMOA-30 film.

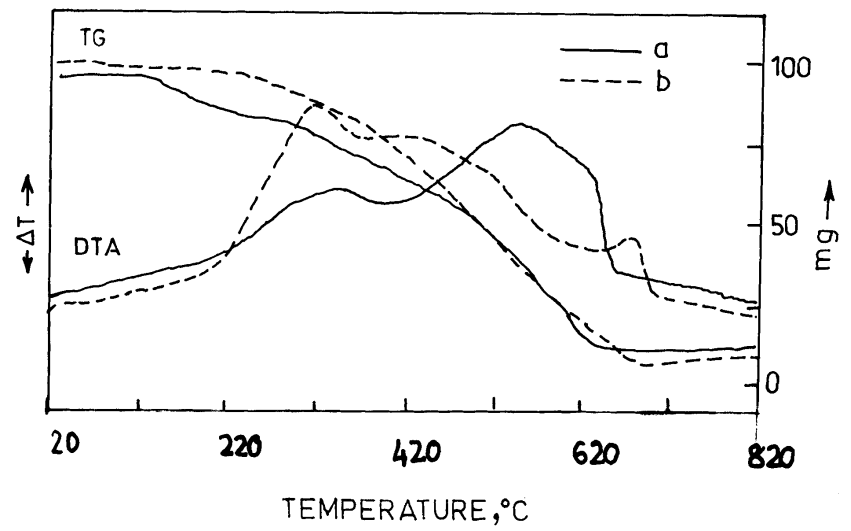

Figure 6. TG-DTA thermogram of (a) PDMOA film and (b) PADMOA-37 film. 
Table 3. Thermal parameter of polymers.

\begin{tabular}{|c|c|c|c|c|c|}
\hline \multirow[b]{2}{*}{ Sample } & \multicolumn{3}{|c|}{ Weight loss } & \multirow[b]{2}{*}{ Maximum decomp. temp. } & \multirow[b]{2}{*}{ Range of decomposition temp } \\
\hline & $25-100^{\circ} \mathrm{C}$ & $200-300^{\circ} \mathrm{C}$ & $400-550^{\circ} \mathrm{C}$ & & \\
\hline PAN & $6-7$ & $7-8$ & $58-60$ & 430,545 & $100-560$ \\
\hline PDMOA & $0-1$ & $2-3$ & $55-56$ & 403,590 & $235-630$ \\
\hline PADMOA-37 & $0-1$ & $28-30$ & $37-39$ & $295,480,556$ & $200-588$ \\
\hline
\end{tabular}
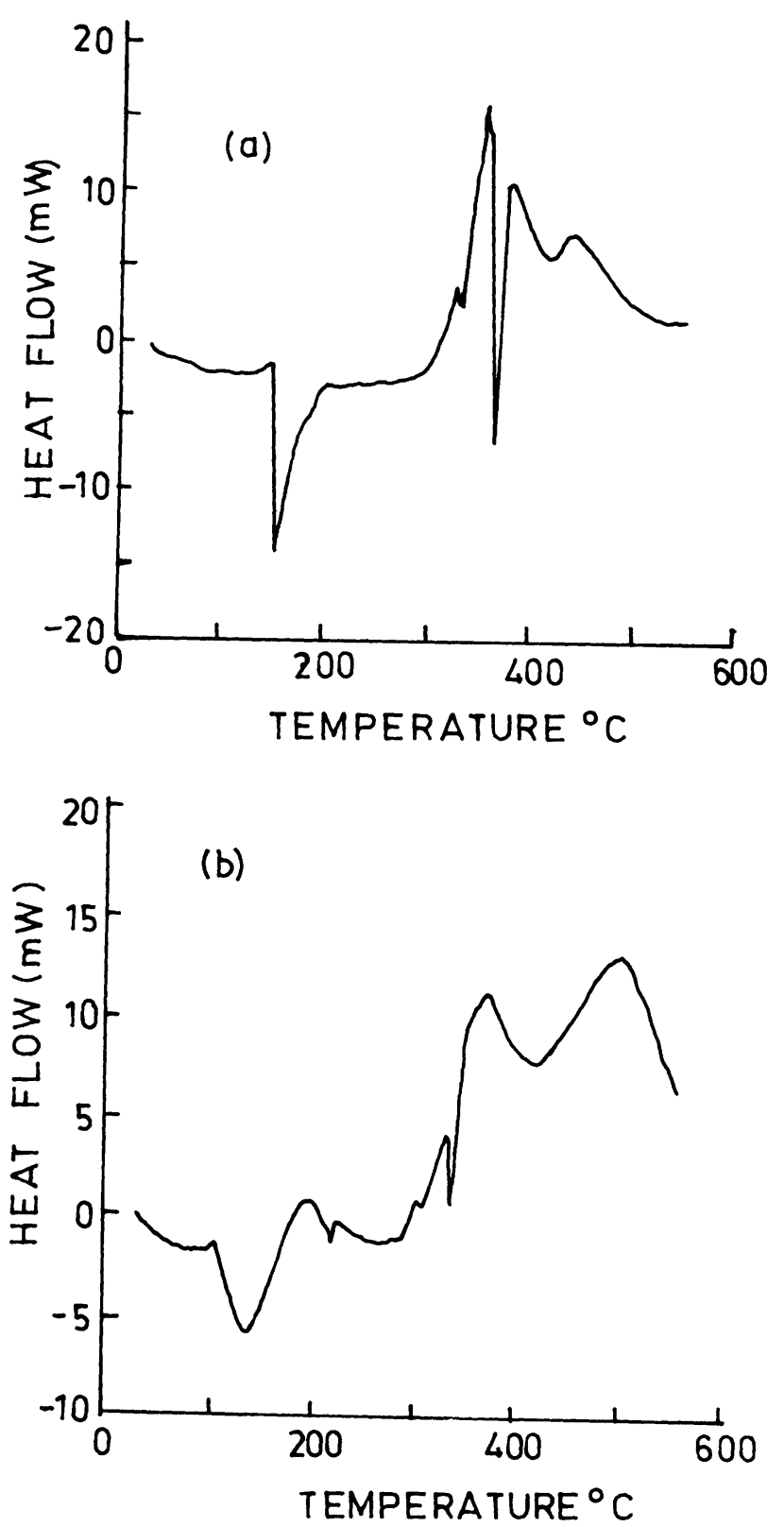

Figure 7. DSC thermogram of (a) PDMOA base and (b) PADMOA-37 base.

et al 1992). Thermal analysis data also suggest that homopolymer is more stable compared to the copolymer PADMOA-37. The extra stability of the homopolymer
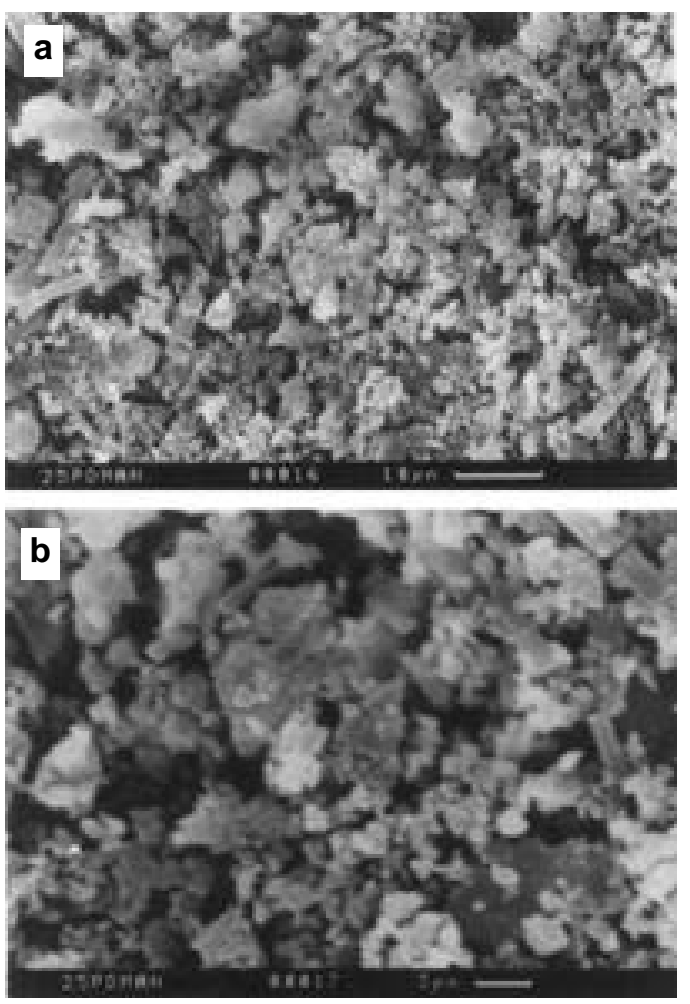

Figure 8. SEM micrographs of PDMOA at magnifications: a. $1500 \times$ and b. $3000 \times$.

could be due to the increased hydrogen bonding between methoxy oxygen and $\mathrm{NH}^{+}$radical cation.

\subsection{Scanning electron micrograph}

In the SEM micrographs (figure 8) at 3000× magnification, a tubular morphology expected of substitute polymers could be recognized. The randomly oriented tubular forms appear to be characteristically different from that of PAN, which has a fibrillar microstructure.

\subsection{ESR spectra}

The ESR spectra (figure 9) of $\mathrm{HCl}$-doped polymer powders indicate that the polymers are strongly paramagnetic with $\mathrm{G}$ values of 2.0022 and 2.0011 and the peak to peak line width $\Delta H_{\mathrm{pp}}$ of 5.5 and $2.0 \mathrm{G}$ for PDMOA-HCl and 
Table 4. XPS binding energy data of polymers.

\begin{tabular}{lcccc}
\hline Polymer & Element & Range, eV & Centre, eV & FWHM, eV \\
\hline PDMOA & $\mathrm{C}_{1 \mathrm{~s}}$ & $280 \cdot 7-290 \cdot 5$ & $285 \cdot 0$ & 3.35 \\
& $\mathrm{~N}_{1 \mathrm{~s}}$ & $394 \cdot 5-402 \cdot 2$ & $398 \cdot 8$ & $2 \cdot 70$ \\
& $\mathrm{O}_{1 \mathrm{~s}}$ & $527 \cdot 0-537 \cdot 5$ & $532 \cdot 6$ & 2.93 \\
PADMOA-30F & & & & \\
& $\mathrm{C}_{1 \mathrm{~s}}$ & $280 \cdot 6-291 \cdot 2$ & $285 \cdot 0$ & 3.31 \\
& $\mathrm{~N}_{1 \mathrm{~s}}$ & $396 \cdot 1-403 \cdot 8$ & $399 \cdot 3$ & 2.96 \\
& $\mathrm{O}_{1 \mathrm{~s}}$ & $528 \cdot 0-537 \cdot 4$ & $531 \cdot 8$ & 3.19 \\
\hline
\end{tabular}

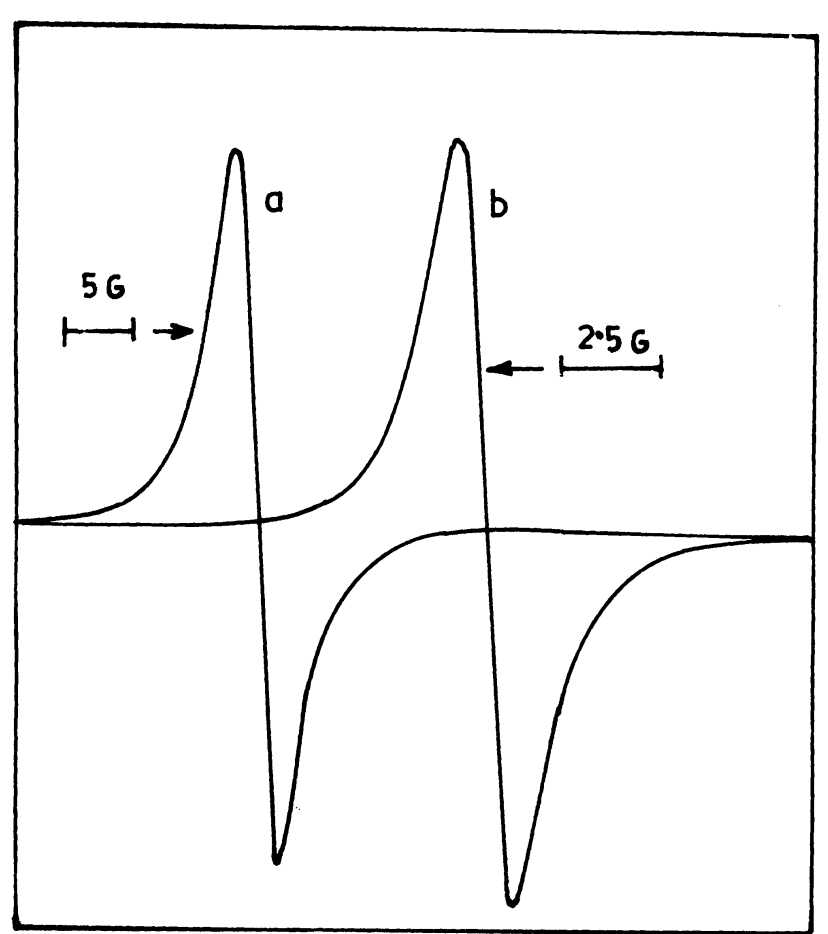

Figure 9. ESR spectra of $\mathrm{HCl}$ doped (a) PADMOA-30 and (b) PDMOA.

PADMOA-HCL-37, respectively (Yue et al 1991; Nguyen et al 1994).

\section{$3.6 \quad X$-ray diffraction}

X-ray diffraction profile (figure 10) of the polymer indicates substantial degree of crystallinity in the doped forms. The base form of the homopolymer is found to have less crystallinity, compared to the doped form. Unit cell parameters, $a, b, c$, defined as in the work of Josefowiez et al (1989), and deduced from observed $2 \theta$ and $d$ values are summarized in table 5 along with the index planes for the orthorhombic crystal cell (Gupta and Umare 1992).

\subsection{X-ray photoelectron spectroscopy}

XPS-core level spectra of $\mathrm{C}_{1 \mathrm{~s}}, \mathrm{~N}_{1 \mathrm{~s}}$ and $\mathrm{O}_{1 \mathrm{~s}}$ are shown in figures 11-13. The $\mathrm{C}$ and oxygen content appears to

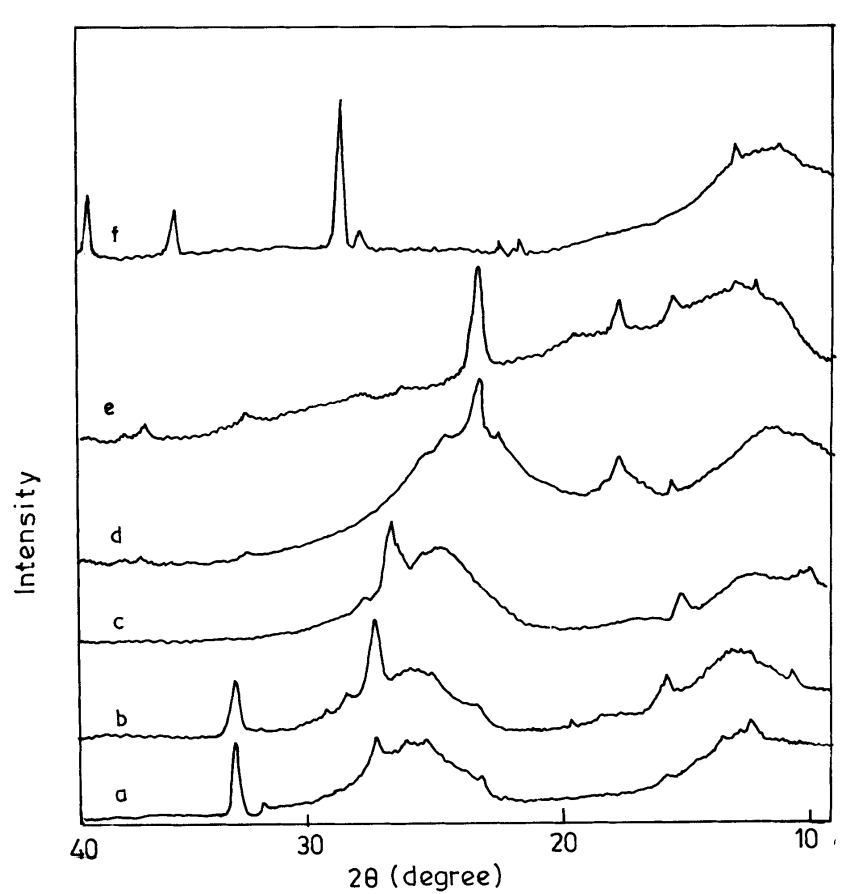

Figure 10. XRD spectra of a. virgin PDMOA, b. PDMOA, c. PDMOA base doped by $\mathrm{HCl}$, d. PDMOA base, e. PADMOA16 base and $\mathrm{f}$. PADMOA-037 base.

be exceedingly high due to contamination (Aldissi and Armes 1992). The $\mathrm{C}_{1 \mathrm{~s}}$ spectra (table 4) are asymmetric and wide $(284 \cdot 6-295 \cdot 1 \mathrm{eV})$ due to the loss of charge to the dopant as a result of protonation. According to the finding energy distribution in the $\mathrm{C}_{1 \mathrm{~s}}$ components can be assigned to $\mathrm{C}-\mathrm{C}, \mathrm{C}-\mathrm{H}, \mathrm{C}-\mathrm{N}, \mathrm{C}=\mathrm{N},=\mathrm{C}-\mathrm{O}, \mathrm{C}-\mathrm{O}, \mathrm{C}=\mathrm{N}^{+}$ and $\mathrm{C}-\mathrm{N}^{+}$etc. In the homopolymer the $\mathrm{N}_{1 \mathrm{~s}}$ peak shows dissymmetry towards lower binding energy which can be attributed to decrease in positive charge on the nitrogen due to delocalisation of $\pi$-electron cloud from the adjoining aryl rings with electron donating methoxy substituents and lower residual doping level compared to copolymer. The $\mathrm{O}_{1 \mathrm{~s}}$ envelope in the homopolymer shows an overall shift to higher BE primarily due to the $\mathrm{C}-\mathrm{O}-\mathrm{C}$ (methoxy) component at $532.5 \mathrm{eV}$ (Chan et al 1993). It also indicates that the oxygen component is associated with positive charge, possibly as a result of being hydrogen bonded to positively charged NH sites. 

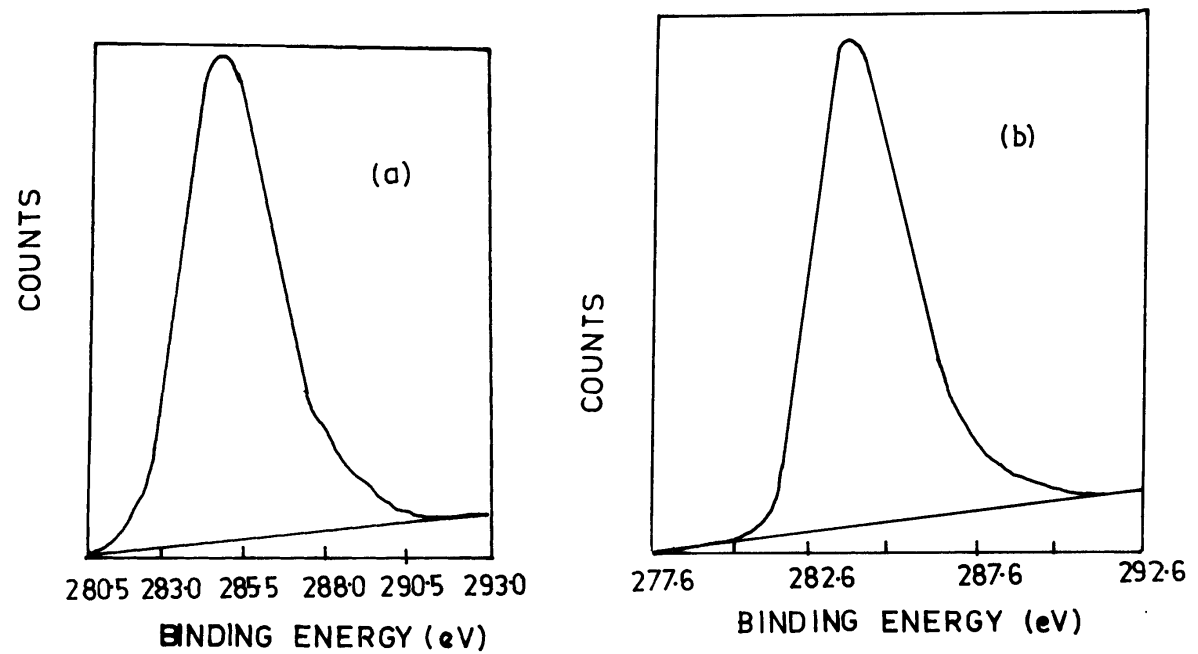

Figure 11. XPS $C_{1 \mathrm{~s}}$ spectra of (a) PDMOA and (b) PADMOA-37 base film.
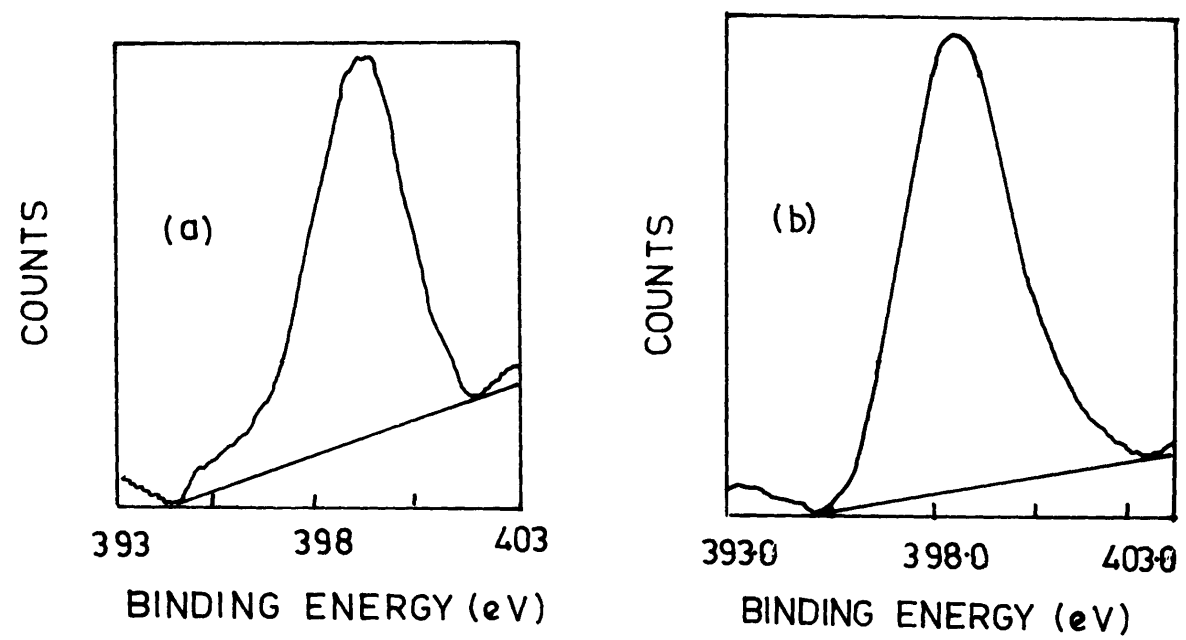

Figure 12. XPS $\mathrm{N}_{\mathrm{ls}}$ spectra of (a) PDMOA base and (b) PADMOA-37 base film.
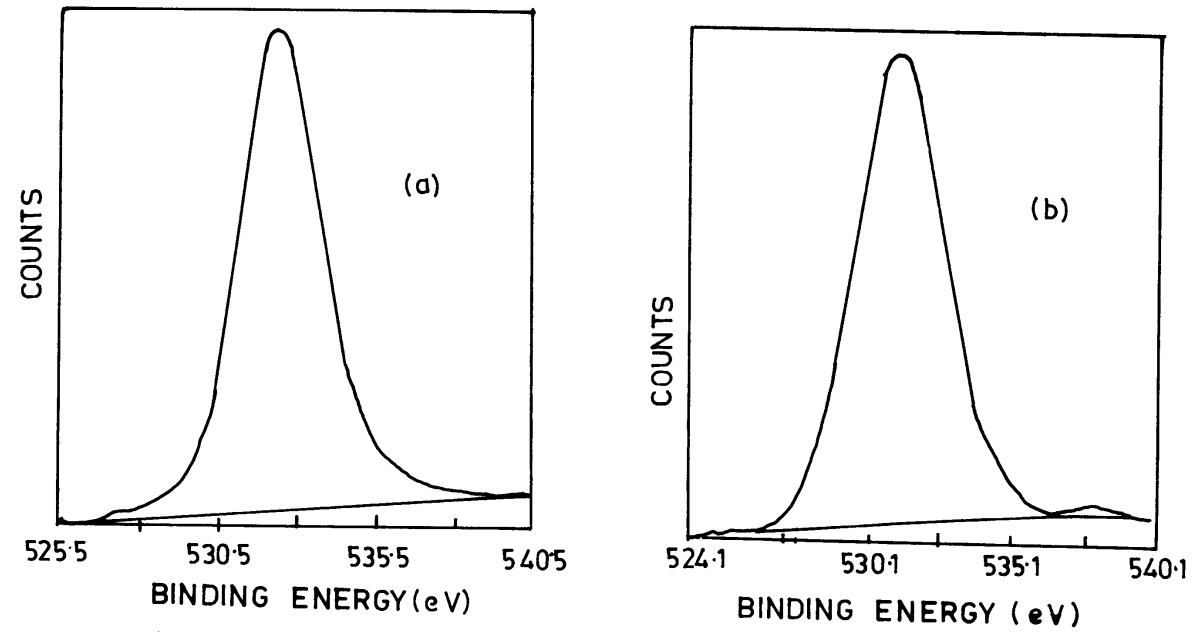

Figure 13. XPS $\mathrm{O}_{\mathrm{ls}}$ spectra of (a) PDMOA base and (b) PADMOA-37 base film. 
Table 5. Crystal structure, lattice parameters and $2 \theta$ values of poly(2,5-dimethoxy aniline).

\begin{tabular}{|c|c|c|c|c|c|}
\hline Sample & $2 \theta$ (observed deg.) & $d \underset{(\AA)}{\text { value (obs.) }}$ & $d$-value (cal.) & $h k l$ & Remarks \\
\hline \multirow[t]{8}{*}{ PDMOA-HCL } & $10 \cdot 68$ & 8.2737 & 8.2397 & 010 & \multirow{8}{*}{$\begin{array}{l}\text { Orthorhombic unit cell dimensions } \\
\qquad \begin{aligned} a & =7 \cdot 7221 \\
b & =8 \cdot 2397 \\
c & =15 \cdot 0428\end{aligned}\end{array}$} \\
\hline & $12 \cdot 15$ & $7 \cdot 2737$ & $7 \cdot 2266$ & 011 & \\
\hline & 13.05 & 6.7759 & 6.8698 & 101 & \\
\hline & $15 \cdot 60$ & 5.6736 & 5.6345 & 110 & \\
\hline & $23 \cdot 00$ & $3 \cdot 8622$ & $3 \cdot 8611$ & 200 & \\
\hline & $25 \cdot 05$ & $3 \cdot 5505$ & $3 \cdot 5332$ & 121 & \\
\hline & $27 \cdot 20$ & $3 \cdot 2746$ & $3 \cdot 2728$ & 122 & \\
\hline & $32 \cdot 70$ & 2.7353 & $2 \cdot 7466$ & 030 & \\
\hline \multirow[t]{7}{*}{ PDMOA-Base } & $11 \cdot 30$ & $7 \cdot 8211$ & $7 \cdot 9614$ & 002 & \multirow{7}{*}{$\begin{array}{l}\text { Orthorhombic unit cell dimensions } \\
\qquad \begin{array}{l}a=6.3993 \\
b=8.5686 \\
c=15.9227\end{array}\end{array}$} \\
\hline & 13.45 & $6 \cdot 5802$ & 6.3993 & 100 & \\
\hline & $16 \cdot 50$ & $5 \cdot 3661$ & $5 \cdot 3076$ & 003 & \\
\hline & $18 \cdot 60$ & 4.7647 & 4.8805 & 111 & \\
\hline & $23 \cdot 40$ & 3.7971 & 3.7727 & 022 & \\
\hline & $24 \cdot 18$ & 3.6763 & 3.6876 & 113 & \\
\hline & $25 \cdot 60$ & 3.4755 & 3.4743 & 121 & \\
\hline
\end{tabular}

\subsection{Electrical conductivity}

The poly(aniline-Co-2,5-dimethoxyaniline) copolymer as expected shows higher conductivity with increasing PAN content.

The homopolymer (PDMOA), however, exhibits rather low electrical conductivity $\left(10^{4} \sigma / \mathrm{cm}\right)$ inspite of (i) being more planar and having greater condition compared to PAN (UV and XRD results), (ii) high doping level (chemical analysis) and (iii) well developed polaronic features (UV, ESR results).

\section{Conclusions}

Poly(2,5-dimethoxyaniline) and its copolymers with aniline were synthesized by oxidative coupling in aqueous protic acid using ammonium persulfate as oxidant. Film casting of polymer bases in NMP solution was obtained. The polymer bases show enhanced solubility in common organic solvents like $\mathrm{CHCl}_{3}$ and $\mathrm{CH}_{2} \mathrm{Cl}_{2}$ and their solutions in concentrated $\mathrm{H}_{2} \mathrm{SO}_{4}$ register moderately high viscosity. These polymers show resistance to thermal changes possibly due to cross-linking reactions taking place involving participation of methoxy groups along with visual imine/amine components. The relative lowering of $\mathrm{N}_{1 \mathrm{~s}}$ binding energy in the XPS spectra of the homopolymer illustrates the effect of electron donating feature of methoxy substituent. The dimethoxy substituted polyanilines exhibit tubular morphology. The base form exhibits lesser planar deformation and hence increased planarity according to XRD results. The doped forms with substantially higher crystallinity are however less planar. The PDMOA polymers thus show fairly developed planarity and conjugation compared with PAN and achieve high doping levels. They are endowed with a well- developed polaronic structure, which is a sequel to the strong paramagnetism, manifested in their ESR spectra. The electrical conductivity nevertheless does not show significant improvement possibly due to the presence of insulating methoxy component, in addition to charge localization through the agency for H-bonding, the occurrence of which is suggested by the results of XPS and thermal analysis.

\section{References}

Aldissi M and Armes S P 1992 Macromolecules 247754

Aurian-Blajeni B, Halleck H C and Jackman B H 1988 J. Appl. Electrochem. 19331

Chan H S O, Ng S C, Sun W S, Tan K L and Tan B T G 1992 Macromolecules 256029

Chan H S O, Ng S C, Sim W S, Sew S H, Tan K L and Tan B T G 1993 Macromolecules 26144

Chan H S O, Ho P K H, Ng S C, Tan B T G and Tan K L 1995 J. Am. Chem. Soc. 1178517

Chiang J C and MacDiarmid A G 1986 Synth. Met. 13193

Cromack K R et al 1991 Macromolecules 244157

Diaz A F and KanaZawa K K 1983 Extended linear chain compounds (New York: Plenum) Vol. 3

Focke W W, Wnek G E and Wei Y 1987 J. Phys. Chem. 91 5813

Genies E M, Boyle A, Lapkowski M and Tsintavis C 1990 Synth. Met. 36139

Gupta C M and Umare S S 1992 Macromolecules 25138

Hagiwara T, Yamaura M and Iwata K 1988 Synth. Met. 25243

Josefowiez M E, Laversanne R, Javadi H H S, Epstein A J, Poujet J P, Tang X and MacDiarmid A G 1989 Phys. Rev. B39 12958

Leclerc M, Aprano G D and Zotti Z 1993 Synth. Met. 551527 MacDiarmid A G, Chiang J C and Epstein A J 1989 Faraday Discuss. Chem. Soc. 88317 
Nguyen M T and Diaz A F 1994 Macromolecules 27 7003

Nguyen M T, Kasai P, Miller J L and Diaz A F 1994 Macromolecules 273625

Olinga T E, Fraysse J, Travers J P, Dufresne A and Pron A 2000 Macromolecules 332107

Ray J K, Dutta Gupta M and Roy B C 1995 Macromolecules 28 1727

Ray J K, Dutta Gupta M, Roy B and Bhowmik L 1999 Synth. Met. 100233

Ruckenstein E and Yin W 2000 Macromolecules 331129

Salaneck W R, Lieberg B, Inganas O, Erlandsson R, Lundstrom I, MacDiarmid A G, Halpern M and Somasiri N L D 1985 Mol. Cryst. Liq. Cryst. 121191
Somasiri N L D and MacDiarmid A G 1988 J. Appl. Electrochem. 1892

Stotheim T A (ed) 1987 Handbook of conducting polymers (New York: Marcel Dekker) Vol. 1

Tang J, Jing X, Wang B and Wang F 1988 Synth. Met. 24231

Wang S L, Wang F S and Ge X H 1986 Synth. Met. 1699

Watanabe A, Mori K, Iwasaki Y and Nakamura Y J 1987 Macromolecules 201793

Wei Y and Hsuch K F 1989 J. Polym. Sci. Polym. Chem. Ed. A27 4351

Yue J, Wang Z H, Cromack K R, Epstein A J and MacDiarmid A G 1991 J. Am. Chem. Soc. 1332665

Zeng W Y, Levon K, Laakso J and Osterholm J E 1994 Macromolecules 277754 